07,01

\title{
Динамика полосы Людерса и разрушение алюминий-магниевого сплава, инициированные концентратором напряжений
}

\author{
(C) А.А. Шибков, М.А. Желтов, М.Ф. Гасанов, А.Е. Золотов \\ Тамбовский государственный университет им. Г.Р. Державина, \\ Тамбов, Россия \\ E-mail: shibkov@tsu.tmb.ru
}

(Поступила в Редакцию 16 мая 2017 г.

В окончательной редакции 5 июля 2017 г.)

\begin{abstract}
Методом видеосъемки со скоростью от 500 до 20000 frames/s исследовали in situ пространственновременную локализацию деформации и разрушение алюминий-магниевого сплава АМг6, инициированные геометрическим концентратором напряжения. Установлено, что концентратор напряжения в форме небольшого надреза глубиной около 1\% ширины плоского образца, является аттрактором полос макролокализованной пластической деформации, начиная с полосы Людерса и заканчивая стартом магистральной трещины. Выявлена ключевая роль пересекающихся макрополос деформации в развитии магистральной трещины. Обсуждаются возможные микромеханизмы вязкого разрушения, связанные с динамикой пересечения деформационных полос.
\end{abstract}

Исследование выполнено за счет гранта Российского научного фонда (проект № 15-12-00035).

DOI: 10.21883/FTT.2018.02.45386.158

\section{1. Введение}

Неустойчивость пластической деформации кристаллических материалов проявляется на различных масштабных уровнях: микро-, мезо- и макроскопическом. На каждом структурном уровне пластическая неустойчивость обусловлена различными механизмами: дискретным термоактивационным характером движения дислокации в поле локальных стопоров [1], динамикой мезоскопических дислокационных скоплений (полос скольжения, двойников и т.д.) $[1,2]$, прерывистым распространением полос макролокализованной деформации типа полос Людерса, полос Портевена-Ле Шателье (ПЛШ) [2-4] и др. Природу локализации пластической деформации в полосах ПЛШ обычно связывают с механизмом динамического деформационного старения, обусловленным взаимодействием подвижных дислокаций с диффундирующими атомами примеси, что характерно для металлических твердых растворов замещения или внедрения $[4,5]$. Для исследования in situ микронных и субмикронных скачков деформации, связанных с динамикой мезоскопических дислокационных скоплений используют высокоразрешающие быстродействующие методы на основе лазерного интерферометра [6-8], индукционного датчика смещения [9], кинофильмирования появления поверхностных ступенек, связанных с выходом дислокационных скоплений $[2,10]$, измерений акустической эмиссии $[11,12]$ и др. Прерывистую деформацию и динамику полос ПЛШ в последнее время исследуют, используя методы лазерной спекловой интерферометрии, термографические, электромагнитные, электрохимические и другие методы $[13,14]$.

Несмотря на интенсивное исследование эффекта ПЛШ и полосообразования за последние три десятилетия, многие вопросы остаются открытыми. Среди них - влияние геометрических концентраторов напряжения, характерных для реальных конструкций, на прерывистую деформацию и образование деформационных полос и роль полос в механизмах вязкого разрушения металлов и сплавов, демонстрирующих прерывистую деформацию. В настоящей работе с помощью высокоскоростных in situ методов регистрации деформационных полос и трещин исследуется динамика полосообразования и разрушения, инициированные геометрическим концентратором напряжения в алюминий-магниевом сплаве АМг6, демонстрирующим прерывистую деформацию ПЛШ при комнатной температуре.

\section{2. Методика}

Образцы промышленного сплава АМг6 (Al-6.15\%Mg$0.65 \% \mathrm{Mn}-0.25 \% \mathrm{Si}-0.2 \% \mathrm{Fe}-0.1 \% \mathrm{Cu}$, wt.\%) вырезали машинным способом из холоднокатаного листа толщиной $0.5 \mathrm{~mm}$. Образцы имели форму двухсторонних лопаток с размерами рабочей части $0.5 \times 3 \times 6 \mathrm{~mm}$. После полировки образцы отжигали при температуре $450^{\circ} \mathrm{C}$ в течение $1 \mathrm{~h}$ и закаливали на воздухе. Результаты исследования рекристаллизованной зеренной структуры сплава представлены в работе [15]. Средний размер зерна составил около $10 \mu \mathrm{m}$. Перед отжигом на боковой поверхности рабочей части образца наносили геометрический концентратор напряжения в виде надреза глубиной 30-40 $\mathrm{m}$, составляющей около $1 \%$ ширины образца. Растяжение образцов с постоянной скоростью роста приложенного напряжения $\dot{\sigma}_{0}=0.2 \mathrm{MPa}$ проводили в „мягкой“ деформационной машине, специально разработанной для изучения ступенчатой деформации и прерывистой ползучести [16]. 
Динамику деформационных макрополос и трещин исследовали in situ с помощью видеосъемки скоростной цифровой видеокамерой FASTCAM Mini UX100 (Photron) поверхности деформируемого металла в косом освещении. Скорость видеосъемки варьировали от 500 до $20000 \mathrm{frames} / \mathrm{s}$ в зависимости от задач исследования: динамика и морфология полосы Людерса, динамика полос ПЛШ и кинетика развития магистральной трещины. Обработка данных видеосъемки состояла в вычитании последовательных цифровых изображений с помощью компьютерной программы [17]. Для получения объемной картины локализации пластической деформации в плоском образце использовали методику видеосъемки с помощью двух зеркал [18], позволяющей получить одновременные изображения противоположных фронтальных поверхностей деформируемого образца. Динамика полосообразования в отсутствие геометрических концентраторов напряжения экспериментально исследована в $[19,20]$ на примере сплава АМг6.

\section{3. Результаты и обсуждение}

На рис. 1 представлены данные видеосъемки со скоростью 500 frames/s процесса локализации пластической деформации на первом деформационном скачке, спонтанно возникшем при напряжении $\sigma_{c} \approx 160 \mathrm{MPa}$, ступени амплитудой около $2 \%$ на кривой нагружения со скоростью $\dot{\sigma}_{0}=0.2 \mathrm{MPa} / \mathrm{s}$ образца сплава АМг6. В рекристаллизованном сплаве $\mathrm{Al}-\mathrm{Mg}$ вне зависимости от режима нагружения (в жесткой машине при $\dot{\varepsilon}_{0}=$ const или мягкой машине при $\dot{\sigma}_{0}=$ const) первый деформационный скачок, как известно [21,22], связан с зарождением и распространением полосы Людерса (ПЛ). В данном случае полоса ПЛ зарождается от геометрического концентратора напряжения на ребре кристалла и в форме узкого клина деформированного материала (зародыша ПЛ) растет поперек образца со скоростью вершины $10 \mathrm{~cm} / \mathrm{s}$ и боковой скоростью около $2 \mathrm{~mm} / \mathrm{s}$ (рис. 1, a, кадры 39-68). После прорастания зародыша ПЛ через все поперечное сечение начинается расширение ПЛ почти на всю рабочую часть образца (кадры 86-163) со средней скоростью около $1 \mathrm{~cm} / \mathrm{s}$ в интервале времени $0.6 \mathrm{~s}$, совпадающем с длительностью фронта первой деформационной ступени на кривой нагружения.

Из результатов компьютерной обработки данных видеосъемки с двумя зеркалами (рис. 1,b) видно, что зародыш ПЛ возникает сначала на одной фронтальной поверхности образца вблизи концентратора (рис. 1, $b$, кадр 51), затем на обеих противоположных поверхностях (кадр 58), причем их изображения смещены вдоль растяжения приблизительно на $0.5 \mathrm{~mm}$. Это означает, что зародыш ПЛ распространяется поперек образца (толщиной $0.5 \mathrm{~mm}$ ) в плоскости, составляющей угол около $45^{\circ}$ к оси растяжения, т. е. представляет собой полосу локализованного сдвига. После прорастания зародыша через поперечное сечение формируется завершенная (сквозная) полоса деформации, которая продолжает расширяться за счет движения ее границ в противоположные стороны. Пластическая деформация локализуется в основном на движущихся границах ПЛ, а область внутри ПЛ в результате деформационного упрочнения уже не деформируется (кадры 71-152). На начальном этапе границы полосы плоские на оптическом уровне, а затем (после 156 кадра) начинают ветвиться и со временем приобретают фрактальную структуру, причем ветвление структуры фронта ПЛ на одной фронтальной поверхности плоского образца не совпадает с таковой на противоположной поверхности, т. е. ветви фронта ПЛ имеют объемный (а не плоский) характер.

В результате распространения ПЛ на всю рабочую часть образца ее поверхность становится матовой со структурой типа „апельсиновой корки“. Последующие макроскачки деформации происходят за счет формирования деформационных полос другой природы - полос Савара-Массона - расширяющихся шеек [17]. В отсутствии геометрического концентратора напряжения деформационные полосы размножаются по каскадному механизму: новые полосы зарождаются на границах предшествующих полос, за исключением первичной полосы, которая зарождается спонтанно в случайной позиции на рабочей части образца $[17,23]$. При наличии геометрического концентратора новые полосы зарождаются не только на границах предшествующих полос, но и вблизи концентратора, как и первичная полоса. Концентратор напряжения играет таким образом роль аттрактора деформационных полос; полосы редко отходят от концентратора к краям рабочей части образца. В то же время в отсутствие концентратора первые полосы зарождаются с большей вероятностью именно на краях рабочей части вблизи лопаток. Структура полос на макроуровне напоминает в среднем по времени латинскую букву „V“ с вершиной вблизи концентратора напряжения (см. рис. 2, кадр 219). Вне этой области локализации пластической деформации происходит в основном однородная упругая деформация.

Типичная картина макролокализации пластической деформации перед разрывом образца на последнем деформационном скачке представлена на рис. 2. Триггером развития макроскачка является зарождение вблизи концентратора напряжения узкой полосы локализованного сдвига (рис. 2, кадры 16, 17), которая после прорастания через поперечное сечение трансформируется в полосу деформации Савара-Массона - расширяющуюся шейку, наклоненную к оси растяжения под углом 60-70 (см. также рис. 2 в работе [17]). Затем границы этой полосы генерируют полосы второго порядка (кадр 68) и т.д. В результате развитие пространственно-временной неустойчивости на фронте последнего деформационного скачка описывается бифуркационным „деревом“, представленным на рис. 3 в виде корреляционной диаграммы - временной зависимости координат границ полос деформации $x$ относительно позиции зарождения первичной полосы-зародыша, т. е. координаты концентратора напряжения. 
39

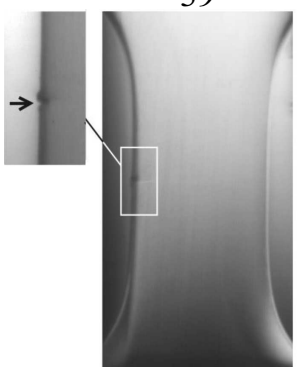

68

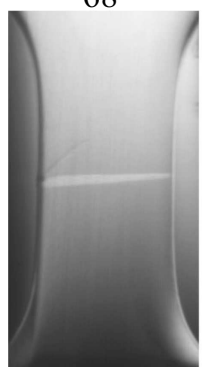

51

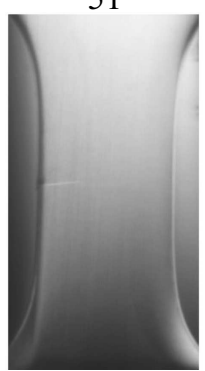

86

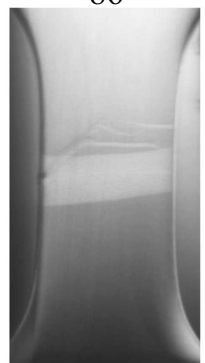

53

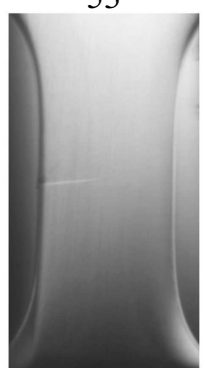

137

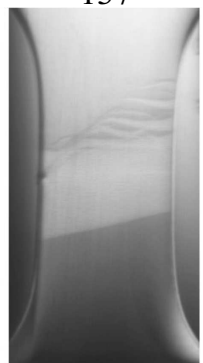

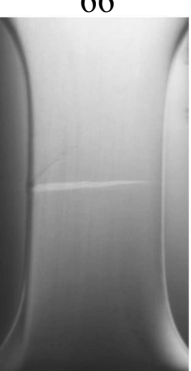

163

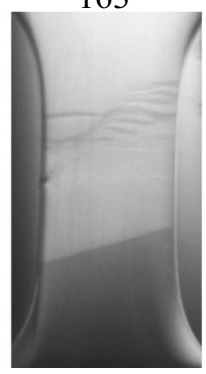

$3 \mathrm{~mm}$
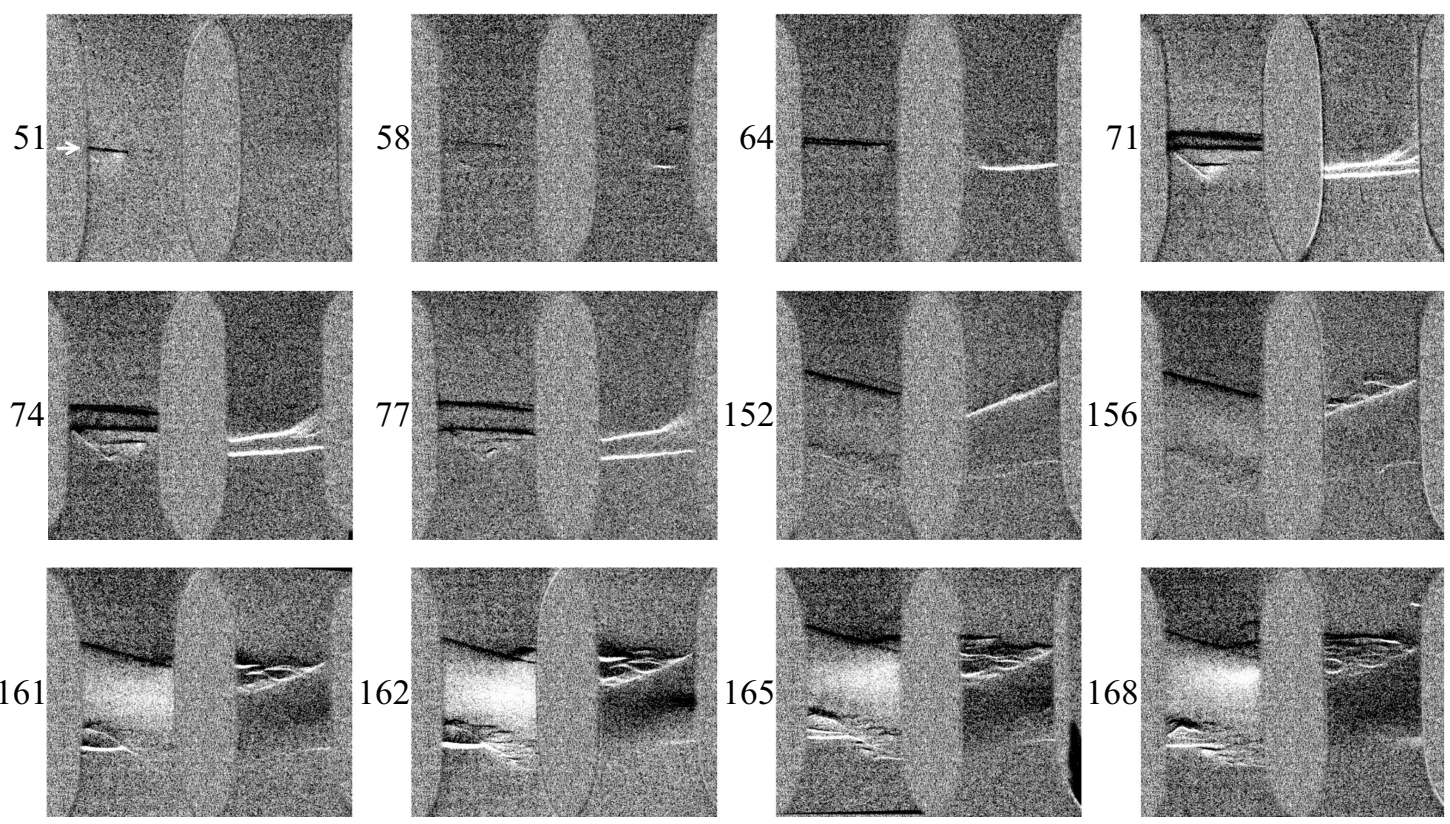

$\stackrel{3 \mathrm{~mm}}{\longmapsto}$

Рис. 1. Фрагмент видеофильма, демонстрирующий зарождение и развитие полосы Людерса от геометрического концентратора напряжения в сплаве АМг6 с рекристаллизованной зеренной структурой. $a$ - без обработки изображений видеофильма, $b-$ с компьютерной обработкой изображений противоположных поверхностей образца, полученных видеосъемкой с помощью двух зеркал. Числа - номера кадров. Скорость видеосъемки 500 frames/s. Стрелками отмечен концентратор в форме надреза глубиной около $30 \mu \mathrm{m} . \sigma_{c}=160 \mathrm{MPa}$.

Для исследования влияния на разрушение пространственного статистического распределения полос деформации строилась гистограмма полос $N\left(x_{i}\right)$. Рабочая часть образца условно разбивалась на 18 эквидистантных сечений $x_{i}$ и подсчитывалось количество границ полос $N\left(x_{i}\right)$ на участке $x_{i+1}-x_{i}$, где $x_{i}$ - координата сечения образца, отсчитанная от сечения, проходящего через концентратор напряжения (рис. 4). Видно, что гистограмма $N\left(x_{i}\right)$ имеет колоколо-подобную форму с максимумом вблизи сечения, проходящем через геометрический концентратор напряжения. Позиция магистральной трещины находится в области максимума гистограммы 

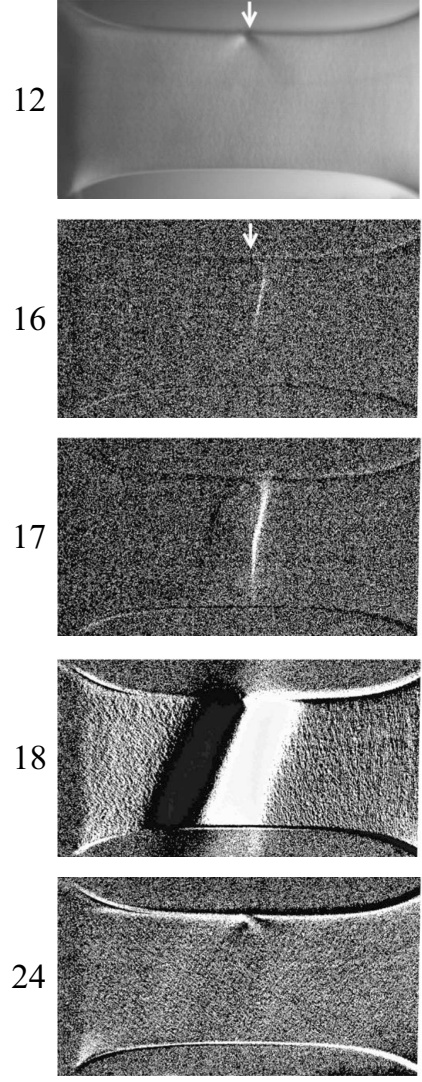

68

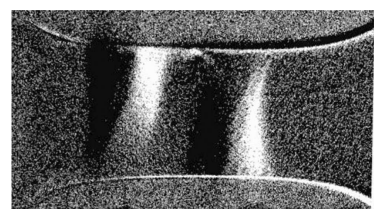

72

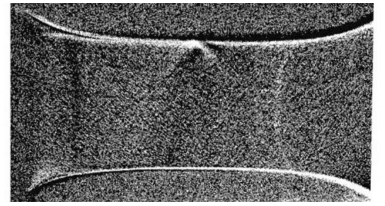

92

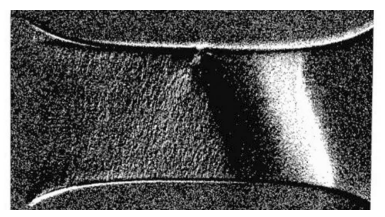

183

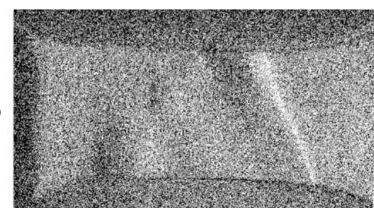

185

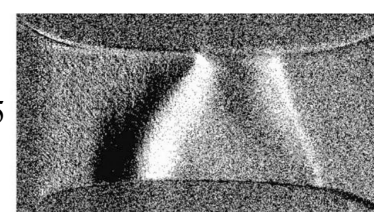

186

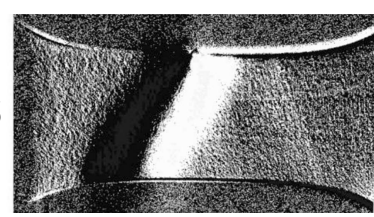

193

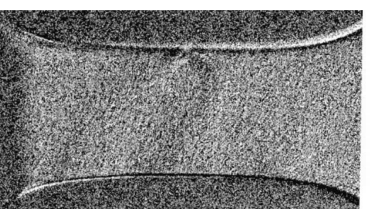

200

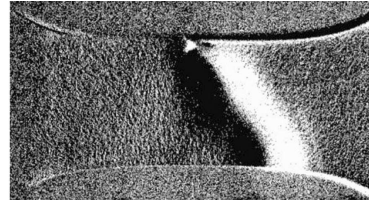

216

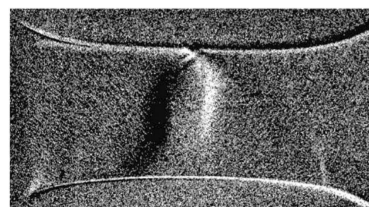

217

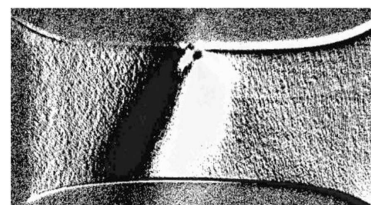

218

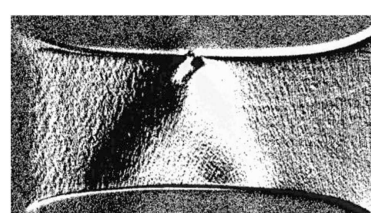

219
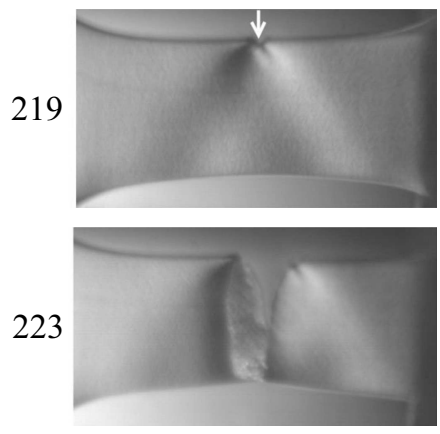

$2 \mathrm{~mm}$

Рис. 2. Развитие деформационных полос на последнем скачке деформации с разрывом образца. Стрелкой отмечен концентратор напряжения. Скорость видеосъемки $500 \mathrm{frames} / \mathrm{s} . \sigma_{B}=320 \mathrm{MPa}$.

и совпадает в пределах пространственного разрешения метода $(\sim 10 \mu \mathrm{m})$ с позицией первичной полосы деформации. Эволюция пространственно-временной структуры полос на последнем скачке деформации имеет по крайней мере две основные стадии: АВ и ВС (см. рис. 3): стадия $\mathrm{AB}$ расширения области макролокализации пластической деформации за счет размножения деформационных полос по каскадному механизму (каждая новая полоса зарождается на границах предыдущей полосы) и стадия ВС образования шейки перед разрывом образца, когда зарождение и расширение новых полос ограничено $\mathrm{V}$-образной областью рабочей части образца с вершиной вблизи концентратора напряжений (кадры 185-219 на рис. 2). Завершающая стадия ВС - стадия макролокализации пластической деформации в окрестности сечения, в котором пройдет магистральная трещина. Гистограмма полос $N\left(x_{i}\right)$ на этой стадии выделена более темным тоном на рис. 4.

Таким образом, небольшой концентратор в виде надреза глубиной $\sim 1 \%$ ширины $w$ образца умень- шает эффективную длину рабочей части, где происходит пластическая деформация, сосредоточенная в полосах. Это уменьшение носит существенно статистический характер: в ходе развития деформационного скачка полосы зарождаются как вблизи надреза, так и на границах предшествующих полос (как в отсутствие искусственного концентратора напряжений $[19,20])$, но с наибольшей вероятностью они заполняют угловой сектор около $60^{\circ}$ с вершиной в области надреза. С геометрической точки зрения линейный размер пластически деформированной области составляет $1.2-1.3 w \approx 3.5-4 \mathrm{~mm}$. Эта оценка подтверждается статистической обработкой гистограммы полос, которая имеет форму близкую к распределению Гаусса. Ширина гауссово-подобной гистограммы (на уровне ее полувысоты), как видно из рис. 4, составляет приблизительно 3-4 $\mathrm{mm}$.

Обсудим возможные механизмы разрушения сплава, учитывающие макролокализацию пластической деформации перед разрывом. В отсутствие концентратора 

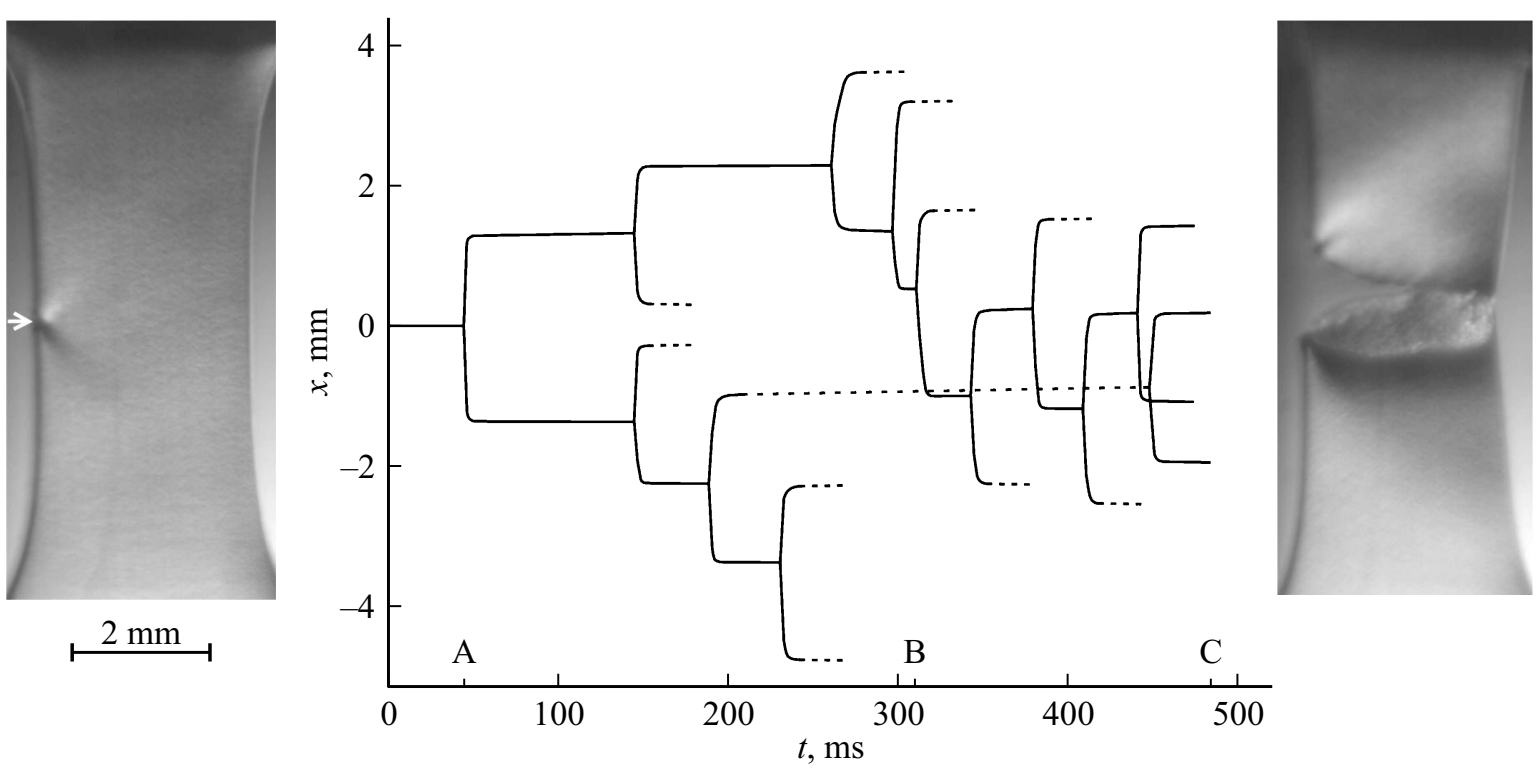

3. Корреляционная диаграмма $x(t)$, демонстрируюшая пространственно-временную эволюцию границ деформационных полос на последнем скачке деформации с разрывом образца. Соответствующий фрагмент видеосъемки представлен на рис. 2. А момент зарождения первичной деформационной полосы от геометрического концентратора напряжения; АВ - временная стадия каскадного размножения полос, ВС - стадия локализации пластической деформации вблизи сечения, через которое пройдет трещина, С - момент старта магистральной трещины.
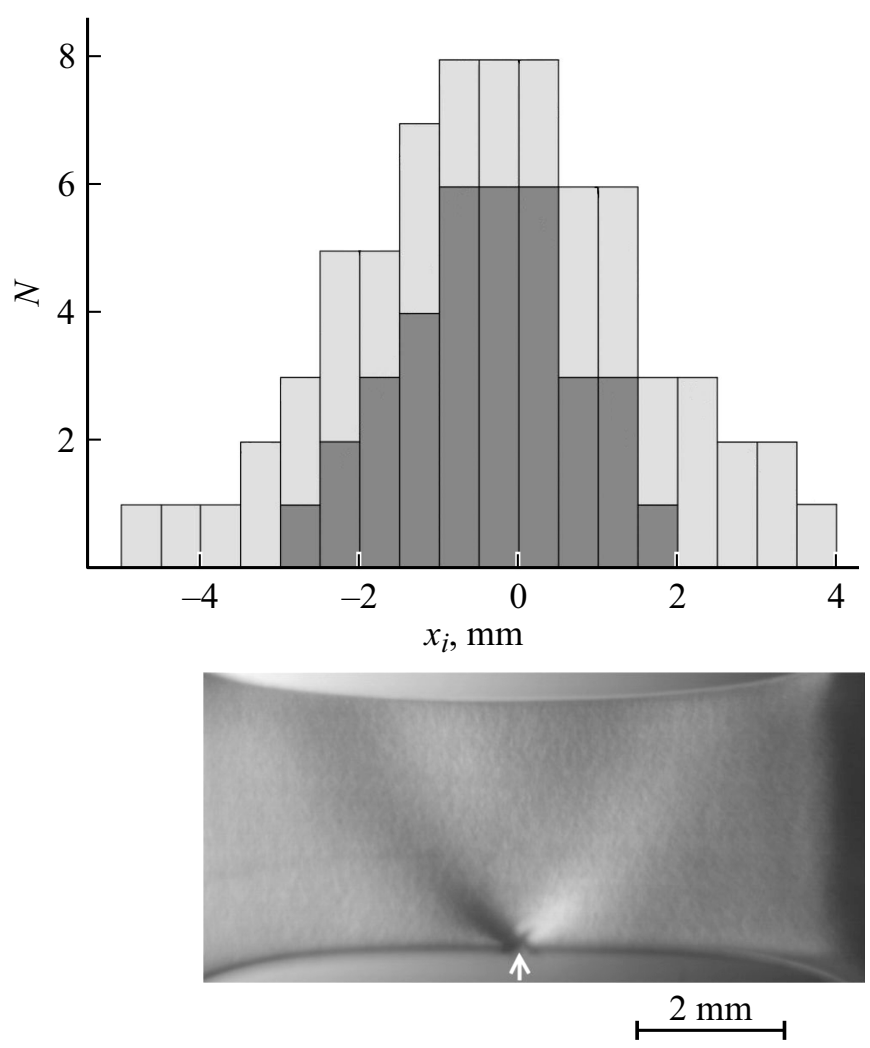

Рис. 4. Гистограмма $N\left(x_{i}\right)$ полос деформации на последнем деформационном скачке с разрывом образца, соответствующем временному интервалу АС на рис. 3. Темно серым тоном выделена часть гистограммы, соответствующая последней стадии локализации деформации ВС. Стрелкой отмечен геометрический концентратор напряжения. напряжения этот вопрос подробно исследован в работах томской школы физиков-прочнистов [24-26] на основе анализа структуры двух макрополос локализованной пластической деформации по схеме креста в сопряженных направлениях максимальных касательных напряжений, которые формируются на стадии образования шейки перед разрывом. При этом основным микромеханизмом разрушения является зарождение несплошностей в окрестности включений вторичной фазы и последующее порообразование на них. Концентратор напряжения, как отмечалось, вызывает формирование макроскопических полос деформации, которые в среднем по времени образуют V-образную структуру локализованной деформации перед разрывом образца. Область вблизи этой структуры представляет область материала, наиболее интенсивно „обработанного“ полосами в сопряженных направлениях максимальных касательных напряжений, составляющих соответственно углы около $+30^{\circ}$ и $-30^{\circ}$ относительно нормального сечения образца (см. рис. 2).

Взаимодействие дислокационных скоплений в области пересечения макрополос, а также взаимодействие скоплений с границами зерен способно вызвать образование микротрещин по механизмам Коттрелла и Зинера-Стро соответственно [27,28]. Эти механизмы дополняют отмеченные выше механизмы микроразрушения, связанные с порообразованием вблизи частиц вторичной фазы (в сплаве АМг6 это частицы $\beta\left(\mathrm{Al}_{3} \mathrm{Mg}_{2}\right)$ фазы [7]). В результате, особенно на завершающей стадии ВС перед разрывом, область пересечения макрополос становится областью материала с повышенной концентрацией микротрещин. Их слияние и приводит 

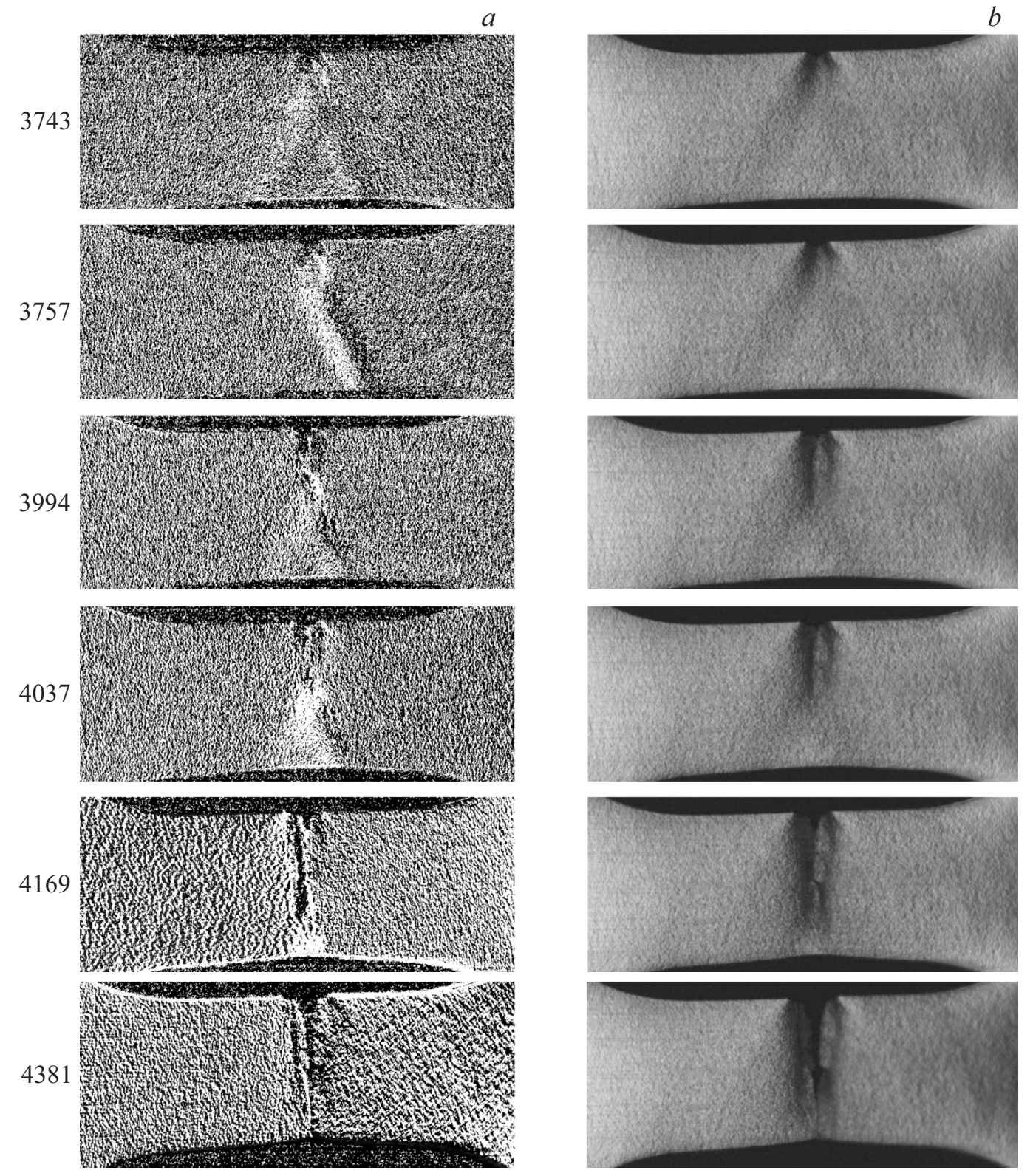

$2 \mathrm{~mm}$

Рис. 5. Фрагмент видеофильма роста магистральной трещины от поверхностного концентратора напряжения, демонстрирующего генерацию деформационных макрополос в момент остановок вершины трещины: $a$ - результаты компьютерной обработки изображений, $b-$ фрагмент того же видеофильма без обработки изображений. Скорость видеосъемки 20000 frames/s. Числа номера кадров.

к развитию магистральной вязкой трещины за счет сваливания дислокаций в ее вершину. При угле между сопряженными макрополосами около $60^{\circ}$ размер области пересечения этих полос очевидно порядка ширины полосы $w_{b} \approx 1.5-2 \mathrm{~mm}$. В этой области стартует магистральная трещина: а) в образце с геометрическим концентратором напряжения - вблизи этого концентратора; б) в образце без концентратора - в центральной части Х-образной структуры сопряженных полос по данным видеосъемки со скоростью 5000 frames/s процесса образования шейки и разрушения в работе [20].
Для исследования влияния полос макролокализованной деформации на процесс разрушения использовали видеосъемку со скоростью 20000 frames/s поверхности деформируемого образца непосредственно в ходе развития магистральной трещины. Из данных видеосъемки, представленных на рис. 5, следует, что движение вершины трещины сопровождается генерированием макрополос пластической деформации. Вершина трещины теперь выполняет роль геометрического концентратора напряжения. В приближении эллиптической формы трещины коэффициент концентрации упругих напряжений 
в вершине трещины, как известно, равен $k=1+2 \sqrt{l / r}$, где $l$ - длина трещины, $r-$ радиус кривизны в ее вершине [29].

В металлах, не демонстрирующих прерывистую деформацию и полосообразование, пластическая релаксация вблизи вершины трещины начинается в двухлепестковой пластической зоне максимальных касательных напряжений в форме „бабочки“ [30]. В мелкозернистых поликристаллических сплавах размер пластической зоны обычно ограничен несколькими зернами (мезоскопический уровень пластической деформации). В сплаве АМг6, демонстрирующем явно выраженную прерывистую деформацию, пластическая зона вблизи вершины стартующей трещины в пределах миллисекунды перерастает в две сопряженные макрополосы, образующие V-образную структуру с вершиной в устье трещины и углом около $60^{\circ}$ между полосами (рис. 5, кадр 3743 ). Объем макрополосы на начальной стадии ее быстрого расширения в образцах сечением $3 \times 0.5 \mathrm{~mm}$ достигает $1.5-2 \mathrm{~mm}^{3}$.

Трещина прорастает через зону пересечения полос перед ее вершиной предположительно за счет слияния микротрещин, образованных по механизмам взаимодействия дислокационных скоплений, принадлежащих сопряженным макрополосам, или взаимодействия скоплений с границами зерен $[27,28,30]$. Затем магистральная трещина останавливается (из-за отсутствия вблизи ее вершины необходимого количества микротрещин) и испускает очередную пару сопряженных макрополос (рис. 5, кадр 3994). После термоактивированного зарождения микротрещин по отмеченным выше механизмам магистральная трещина прорастает через область пересечения этих полос и т.д. Типичная длина скачка магистральной трещины между остановкой и пластической релаксацией составляет $\Delta l_{c r} \approx 0.5-1 \mathrm{~mm}$, а нижняя оценка скорости трещины в скачке $v_{c r} \sim \Delta l_{c r} / \Delta t \approx 10-20 \mathrm{~m} / \mathrm{s}$ ограничена временни́м разрешением видеокамеры $\Delta t=50 \mu$ s при съемке со скоростью $20000 \mathrm{frames} / \mathrm{s}$. Для более детального исследования in situ чередования процессов роста магистральной трещины и зарождения и распространения полос деформации необходимо существенно увеличить быстродействие и пространственное разрешение используемых методов.

Таким образом, вязкая трещина движется скачками на разных масштабных уровнях: макроскопическом, между испусканием вершиной очередной пары сопряженных макрополос, мезоскопическом, за счет слияния микротрещин в области пересечения макрополос и микроскопическом, за счет поглощения деформационных микропор вблизи включений и т.д.

Описанная картина „эстафетного“ чередования процессов разрушения и пластической релаксации качественно согласуется с результатами работы [31], в которой исследовалась in situ в колонне растрового электронного микроскопа совместно с методом АЭ динамика скачкообразного роста магистральной трещины в модельном материале (эпоксидной смоле) на микро и мезоскопическом структурном уровне. По мнению авторов [31] формирование магистральной трещины определяется динамическим соотношением между освобождаемой энергией в дискретном акте структурной перестройки и диссипативными свойствами ближайшего окружения или системы в целом. Из результатов настоящей работы следует, что и для материала, демонстрирующего прерывистую деформацию и полосообразование на макроуровне процессы локализации пластической деформации и разрушения оказываются взаимообусловленными, поддерживающими друг друга в многоуровневой иерархической структуре разрушающегося материала от микро- до макроуровня.

\section{4. Заключение}

На основе прямого наблюдения деформационных полос и трещин с помощью высокоскоростной видеосъемки со скоростью до 20000 frames/s исследовали влияние геометрического концентратора напряжения в виде небольшого надреза глубиной около $1 \%$ ширины образца на развитие пространственно-временной локализации пластической деформации и разрушения алюминий-магниевого сплава АМг6, демонстрирующего прерывистую деформацию и полосообразование при комнатной температуре. Установлено, что геометрический концентратор является аттрактором макрополос пластической деформации, начиная с полосы Людерса и заканчивая формированием шейки перед разрывом образца. Предполагается, что магистральная трещина растет за счет слияния микротрещин, зарождающихся преимущественно по механизму взаимодействия дислокационных скоплений в области пересечения сопряженных макрополос, которые образуют V-образную структуру с вершиной сначала в области геометрического концентратора напряжений, а затем в вершине растущей магистральной трещины.

\section{Список литературы}

[1] Динамика дислокаций. Наук. думка, Киев (1975). 404 с.

[2] H. Neuhauser. Dislocation in Solids / Ed. F.R.N. Nabarro. North-Holland Company, Amsterdam 6, 319 (1983).

[3] K. Chihab, Y. Estrin, L.P. Kubin, J. Vergnol. Scripta Met. 21, 203 (1987)

[4] L.P. Kubin, Y. Estrin. Acta Met. 33, 3, 397 (1985).

[5] Y. Estrin, L.P. Kubin. Continuum models for materials with microstructure / Ed. H.-B. Muhlhaus. Wiley \& Sons, N.Y. (1995). P. 395.

[6] В.В. Шпейзман, Н.Н. Песчанская, В.А. Степанов. ФТТ 26, 8, 2387 (1984).

[7] Н.Н. Песчанская, П.Н. Якушев, В.В. Шпейзман, А.Б. Синани, В.А. Берштейн. ФТТ 41, 5, 848 (1999).

[8] Н.Н. Песчанская, В.В. Шпейзман, А.Б. Синани, Б.И. Смирнов. ФТТ 46, 11, 1991 (2004).

[9] Л.И. Даниленко, М.В. Зиновьев, В.А. Коваль. ПТЭ 2, 213 (1973). 
[10] A. Hampel, H. Neuhauser. Phys. Status Solidi A 100, 1, 441 (1987).

[11] J. Weiss, J.-R. Grasso. J. Phys. Chem. B 101, 32, 6113 (1997).

[12] В.С. Бойко, Р.И. Гарбер, В.Ф. Кившик. ФТТ 17, 5, 1541 (1975).

[13] Л.Б. Зуев, С.А. Баранникова. Физика прочности и экспериментальная механика. Наука, Новосибирск (2011). 350 с.

[14] A.J. Yilmaz. Sci. Technol. Adv. Mater. 12, 1 (2011).

[15] А.А. Шибков, А.А. Мазилкин, С.Г. Протасова, Д.В. Михлик, А.Е. Золотов, М.А. Желтов, А.В. Шуклинов. Деформация и разрушение материалов 5, 24 (2008).

[16] А.А. Шибков, М.А. Лебедкин, М.А. Желтов, В.В. Скворцов, Р.Ю. Кольцов, А.В. Шуклинов. Заводская лаборатория. Диагностика материалов 71, 20 (2005).

[17] А.А. Шибков, А.Е. Золотов. Письма в ЖЭТФ 90, 412 (2009).

[18] А.А. Шибков, А.Е. Золотов, М.А. Желтов. ФТТ 52, 2223 (2010).

[19] А.А. Шибков. Нелинейная механика и разрушение промышленных сплавов Al-Mg. ТГУ, Тамбов (2010). 143 с.

[20] А.А. Шибков, А.Е. Золотов, М.А. Желтов, А.В. Шуклинов, А.А. Денисов. ФТТ 53, 1873 (2011).

[21] F.B. Klose, F. Hagemann, P. Hähner, H. Neuhäuser. Mater. Sci. Eng. A 387-389, 93 (2004).

[22] F. Chmelik, F.B. Klose, H. Dierke, J. Sachl, H. Neuhauser, P. Lukac. Mater. Sci. Eng. A 462, 53 (2007).

[23] A.A. Shibkov, M.F. Gasanov, M.A. Zheltov, A.E. Zolotov, V.I. Ivolgin. Int. J. Plast. 86, 37 (2016).

[24] В.Е. Панин, Л.С. Деревягина, Е.Е. Дерюгин, А.В. Панин, С.В. Панин, Н.А. Антипина. Физ. мезомех. 6, 97 (2003).

[25] В.Е. Панин, Ю.В. Гриняев. Физ. мезомех. 6, 9 (2003).

[26] Л.С. Деревягина, В.Е. Панин, А.И. Гордиенко. Физ. мезомех. 10, 59 (2007).

[27] A.H. Cottrell. Trans. Met. Soc. AIME. 38, 192 (1958).

[28] A.N. Stroh. Proc. Roy. Soc. A 223, 404 (1954).

[29] В.3. Партон. Механика разрушения. Изд-во ЛКИ, М. (2010). $240 \mathrm{c}$.

[30] В.И. Владимиров. Физическая природа разрушения металлов. Металлургия, М. (1984). 280 с.

[31] А.М. Лексовский, Б.Л. Баскин. ФТТ 53, 6, 1157 (2011). 